\title{
Adiponectin and end-stage renal disease
}

\author{
Anastasia Markaki, Emmanuel Psylinakis, Aspasia Spyridaki \\ Department of Nutrition and Dietetics, Technological Educational Institute of Crete, Greece
}

\begin{abstract}
Adiponectin (ADPN) is an adipokine with significant anti-inflammatory, insulin-sensitizing and anti-atherogenic properties, which is generally associated with a beneficial cardiometabolic profile. Paradoxically, end-stage renal disease (ESRD) is characterized by markedly increased plasma ADPN levels and increased cardiovascular risk. In spite of the cardioprotective properties attributed to adiponectin, cardiovascular complications remain the main cause of mortality in the ESRD population. Furthermore, these patients have enhanced chronic inflammation, increased insulin resistance and persistent protein-energy wasting. Studies of the impact of ADPN on clinical outcomes among ESRD patients have so far yielded contradictory results. This review article summarizes the current knowledge on ADPN functions and explores the role of ADPN in ESRD patients, with specific focus on inflammation, insulin resistance, cardiovascular disease and wasting.
\end{abstract}

Key words: Adiponectin, Cardiovascular Disease, Inflammation, Insulin Resistance, Wasting

\section{INTRODUCTION}

Over the last few years, research has shed much light on the role of adipose tissue, which was previously considered a site of pure energy storage. In fact, adipose tissue is now recognized as a major endocrine gland that secretes several bio-active mediators, known as adipokines, with diverse metabolic functions. ${ }^{1}$ Adiponectin is one of the most important adipokines, involved in multiple biological processes in the human body. ${ }^{2}$ It is the most abundant adipose tissue protein in human plasma and has significant anti-inflammatory, insulin-sensitizing and anti-atherogenic properties. ${ }^{3,4}$ In the general population, increased circulating adiponectin levels are generally associated with a beneficial cardiometabolic profile,

\section{Address for correspondence:}

Anastasia Markaki, Department of Nutrition and Dietetics,

Technological Educational Institute of Crete, Greece

E-mail: anmarkaki@staff.teicrete.gr

Received: 21-06-2016, Accepted: 06-09-2016 whereas decreased levels are found in conditions such as type 2 diabetes, coronary artery disease and obesity. ${ }^{5}$ Contrary to expectations, plasma adiponectin levels are high in chronic kidney disease (CKD) and especially end-stage renal disease (ESRD). ${ }^{6,7}$

Reduced renal function is a significant risk factor for cardiovascular events and mortality in CKD patients and this risk is further increased when CKD has progressed to ESRD, requiring dialysis initiation or kidney transplantation. ${ }^{8}$ Despite significant technical improvements in both hemodialysis (HD) and peritoneal dialysis (PD), the mortality rate in ESRD patients is still high. ${ }^{9}$ These patients have enhanced chronic inflammation, increased insulin resistance and increased cardiovascular risk, ${ }^{10}$ in spite of the elevated adiponectin plasma levels. It is not yet clear if the increase in plasma adiponectin depends on accumulation of this protein or represents a counter-regulatory response to the several metabolic and hemodynamic risk factors of renal insufficiency. 
This review article explores the function of adiponectin and how it intersects with inflammation, insulin resistance, cardiovascular disease, wasting and outcome in patients with end-stage renal disease.

\section{ADIPONECTIN STRUCTURE AND ISOFORMS}

Adiponectin is encoded by the APM1 gene (AdiPose Most abundant Gene transcript 1), which is located on chromosome $3 \mathrm{q} 27$, a region linked to genetic susceptibility to type 2 diabetes and obesity. ${ }^{11}$ Adiponectin is a $30 \mathrm{kDa}$ protein composed of 244 amino acids which structurally belongs to the soluble defense collagen superfamily. ${ }^{12}$ Its structure comprises 4 domains. ${ }^{3,13,14}$ It consists of an amino-terminal signaling peptide domain, that targets the hormone for secretion outside the cell, a short hypervariable region, a 65-amino acid-long collagenous domain and a carboxy-terminal globular domain, which facilitates adiponectin binding to its receptors. ${ }^{3}$

Adiponectin circulating in plasma exists as homooligomers of various molecular weights, as well as a proteolytic cleavage fragment, called globular adiponectin, ${ }^{15}$ which represents a small amount of total circulating adiponectin. ${ }^{16}$ Globular adiponectin contains the globular head without the collagen-like domain and has increased binding in myocytes and skeletal muscle membranes, but reduced binding in hepatocytes and liver membranes. Full length adiponectin assembles in three different oligomers: a low molecular weight trimer (LMW), which consists of three adiponectin molecules that bind through their collagen domain, a hexamer generated from two trimers via disulphide bonds within the collagen stalk (middle-molecular-weight adiponectin, MMW) and a bouquet-like 12-18-meric high-molecular-weight (HMW) isoform assembled from MMW oligomers. ${ }^{17}$ The various isoforms exert markedly different biological functions. ${ }^{18}$

\section{ADIPONECTIN RECEPTORS AND FUNCTION}

Adiponectin exerts multiple biological effects throughout the body mediated by two major receptors, AdipoR1 and AdipoR2. AdipoR1 is a high-affinity receptor for globular adiponectin and a low-affinity receptor for full-length adiponectin, while AdipoR2 is an intermediate-affinity receptor for full-length and globular adiponectin. ${ }^{19}$
Both AdipoR1 and AdipoR2 are highly expressed in many tissues and organs. AdipoR1 is abundantly expressed in skeletal muscle, liver and macrophages and is linked to activation of AMP-activated kinase (AMPK) pathways that inhibit gluconeogenesis. ${ }^{20}$ AdipoR2 is most commonly found in the liver, white adipose tissue and vasculature. AdipoR2 seems to be more closely associated with the activation of peroxisome proliferator-activated receptor alpha (PPARa) pathways that promote fatty-acid combustion and energy consumption, as well as inhibition of inflammation and oxidative stress..$^{21-23}$

Besides functioning in peripheral tissues, adiponectin has also been found to act in the central nervous system to regulate appetite and energy expenditure. Both AdipoR1 and AdipoR2 are detected in the paraventricular hypothalamus, the arcuate and lateral hypothalamic nuclei, suggesting a physiological involvement of adiponectin action in these brain regions. ${ }^{24,25}$ Although there is still some ambiguity regarding the bioactive oligomer of adiponectin in the brain, growing evidence indicates that the LMW isoform may be the active form. ${ }^{26,27}$ According to Kubota and colleagues, the LMW isoform plays a major role in regulating feeding behavior in the central nervous system. Hence, it appears that while adiponectin's peripheral effects are mediated predominantly by HMW multimers, LMW forms may be responsible for its central effects. In conclusion, the adiponectin signaling pathway depends on the molecular form of adiponectin, on the relative abundance of its receptors and on the target tissue.

\section{CIRCULATING ADIPONECTIN LEVELS IN ESRD PATIENTS}

Adiponectin is normally present in human plasma at a relatively high concentration, ranging from 2 to $20 \mu \mathrm{g} / \mathrm{ml}$, constituting $0.01 \%$ of the total plasma protein pool. ${ }^{28}$ Adiponectin is excreted via kidney glomerular filtration. ${ }^{29}$ Several clinical studies have confirmed an inverse association between circulating adiponectin and renal function in Africans, Caucasians and Asians (Table 1). ${ }^{7,30-35}$ Since the gradual increase of plasma adiponectin concentration parallels the progression of CKD, the highest levels are found in ESRD patients..$^{36,37}$ In hemodialysis and peritoneal dialysis patients, adiponectin concentrations are about three times higher than in healthy subjects. ${ }^{7,38}$ How- 
Table 1. Studies on circulating adiponectin levels (mean $\pm \mathrm{SD} \mu \mathrm{g} / \mathrm{mL}$ ) in specific ethnic groups according to renal state

\begin{tabular}{llccc}
\hline Ethnic group & Study & Healthy & CKD & ESRD \\
\hline Caucasians & Lara-Castro et a ${ }^{30}$ & $9.4 \pm 3.2$ & & \\
& Zoccali et al ${ }^{7}$ & $6.3 \pm 2$ & & $15 \pm 7.7$ \\
& Zoccali et a ${ }^{31}$ & $5.9 \pm 2.6$ & $12.3 \pm 7.2$ & \\
& Rao et a $\left.\right|^{32}$ & & & $16.8 \pm 8.1$ \\
Africans & Lara-Castro et a ${ }^{30}$ & $8.2 \pm 3.4$ & & \\
& Doumatey et a ${ }^{33}$ & & $10.4 \pm 6.1$ & $17.7 \pm 9.8$ \\
& Rao et a ${ }^{32}$ & & & \\
Asians & Lim et al ${ }^{34}$ & $9.2 \pm 4.2$ & $10.4 \pm 7.4$ & $19.6 \pm 7.4$ \\
& Park et al ${ }^{35}$ & & & \\
\hline
\end{tabular}

ever, there is no significant difference in adiponectin levels between hemodialysis and peritoneal dialysis patients. Moreover, levels of the HMW isoform are also elevated in ESRD, although the distribution of all the adiponectin isoforms in ESRD has not thus far been well studied. ${ }^{39}$

Serum adiponectin levels are significantly lower in males than in females, in patients with obesity, insulin resistance, type 2 diabetes mellitus, coronary artery disease and essential hypertension. ${ }^{40-44}$ Adiponectin levels correlate significantly with several metabolic factors. Similarly to the general population, adiponectin levels in CKD patients are associated positively with high-density lipoprotein cholesterol (HDL) and negatively with triglyceride levels, body mass index (BMI), insulin levels, low-density lipoprotein cholesterol (LDL), C-reactive protein (CRP) and left ventricular mass index. ${ }^{45,46}$ As in the case of healthy subjects, significant negative correlations have been found between plasma adiponectin and both total and truncal fat mass in CKD patients. ${ }^{37}$ Furthermore, in PD patients, adiponectin levels have been found to be inversely associated with D4/D0 glucose and duration of PD treatment. ${ }^{47}$

The underlying cause of the higher levels of circulating adiponectin in kidney disease is still unclear. It has been postulated that the elevated adiponectin levels observed in ESRD are a reflection of decreased renal clearance. ${ }^{48}$ An inverse relationship between adiponectin levels and glomerular filtration rate (GFR) exists in patients with CKD. ${ }^{49}$ There is also a negative correlation between adiponectin levels and residual renal function in patients on peritoneal dialysis. ${ }^{38}$ Moreover, adiponectin levels decrease after kidney transplantation, implying that the kidneys play an important role in the biodegradation or elimination of this protein. ${ }^{50}$ However, Malyszko and colleagues found that in hemodialysis patients, the more adequately dialysed patients have higher adiponectin levels and that this is correlated with a reduction in mortality. ${ }^{51}$

According to Cantarin and coworkers, increased plasma adiponectin levels observed in ESRD are accompanied by an increase in adiponectin protein and mRNA expression in human subcutaneous and visceral adipose tissues, suggesting that there is a stimulus to produce more adiponectin protein despite elevated plasma levels..$^{52}$ A recent study demonstrated that there is higher expression of AdipoR 1 in muscle tissue of ESRD patients compared to controls with normal kidney function. ${ }^{53}$ Increased adiponectin production and increased AdipoR1 receptor expression, despite increased adiponectin levels, indicate that uremia confers adiponectin resistance. Furthermore, the same authors found that there is disruption in the normal adiponectin signaling pathway following phosphorylation of AMPK compared to subjects with normal renal function. Further research is necessary to determine the role of increased adiponectin production in ESRD patients.

\section{ADIPONECTIN AND INSULIN RESISTANCE IN ESRD}

Adiponectin exerts its insulin-sensitizing activity through increasing fatty acid oxidation in skeletal muscle by the sequential activation of AMPK, p38 mitogen-activated protein kinase and PPARalpha. ${ }^{55}$ Despite the elevated adiponectin levels, insulin resistance is frequently recognized in uremic patients..$^{55}$ 
Insulin resistance in uremia is mainly characterized by peripheral tissue insensitivity to insulin with normal hepatic gluconeogenesis and normal uptake of glucose by the liver. ${ }^{56}$ Insulin resistance is an independent predictor of cardiovascular mortality in ESRD and is linked to protein energy wasting and malnutrition. ${ }^{57-59}$ Several studies propose that the percentage of the HMW moiety is the most important correlate of insulin sensitivity. ${ }^{60,61}$

In ESRD patients, serum adiponectin levels correlate negatively with the truncal (i.e., visceral) fat mass, the fat tissue depot considered to be the most metabolically active and which has been identified as a key factor in the development of insulin resistance. ${ }^{62}$ Moreover, lower adiponectin levels are associated with insulin resistance among CKD patients and hemodialysis patients. ${ }^{63,64}$ Shen and colleagues found that in ESRD patients there is an increased proportion of the HMW moiety and that the adiponectin/receptor system appears to be up-regulated in ESRD, possibly as an appropriate counter-regulatory response to the uremic milieu. ${ }^{39}$ However, a recent study by Giers and coworkers found no relationship between insulin resistance and adiponectin concentration, including total adiponectin concentration, the concentration of HMW adiponectin and its percentage in total adiponectin. ${ }^{65}$

On the other hand, hyperadiponectinemia, associated with the inability to lower plasma glucose levels and blunted hepatic AMPK response to adiponectin, delineates a condition of adiponectin resistance. ${ }^{66}$ Adiponectin resistance has also been suggested as a player in obesity-induced insulin resistance ${ }^{67,68} \mathrm{In}$ visceral fat and muscle of ESRD patients, AdipoR1 mRNA expression is increased, whereas expression of AdipoR2 is not modified by uremia. ${ }^{52}$ Thus, adiponectin resistance with high levels of adiponectin but relatively low AdipoR2 may contribute to an impairment of adiponectin-stimulated fatty acid oxidation and lead to insulin resistance.

\section{ADIPONECTIN AND INFLAMMATION IN ESRD}

Adiponectin is considered to be the main antiinflammatory adipokine produced by white adipose tissue. ${ }^{69}$ Its numerous actions include reduction of the phagocytic activity of macrophages and inhibition of the production of inflammatory cytokines from mac- rophages and adipose tissue. However, the prevalence of inflammation is high in ESRD patients. ${ }^{70}$ Although elevated adiponectin levels could be explained by a compensatory response of the organism to inflammation, some researchers propose a bidirectional role of adiponectin (pro-inflammatory and anti-inflammatory) depending on the ratio of the isoforms. ${ }^{71}$ According to Almer et al, the anti-inflammatory effect of adiponectin might depend on the concentration of globular adiponectin. ${ }^{72}$

Several studies demonstrate that low levels of adiponectin are associated with inflammation in ESRD. ${ }^{73-75}$ Significant negative correlations have been found between plasma adiponectin and inflammatory parameters such as CRP, suggesting that hypoadiponectinemia may serve as a marker of increased inflammatory status in ESRD patients. It may be possible that the anti-inflammatory protective effects of adiponectin cannot compensate for the aggravating inflammatory status that characterizes these patients. Alternatively, factors contained in the uremic and the proinflammatory environment may block the adiponectin signal transduction pathway, conferring adiponectin resistance. ${ }^{52,53}$ Since AdipoR2 is the receptor involved in the inhibition of oxidative stress and inflammation, ${ }^{22}$ adiponectin resistance with high levels of adiponectin but relatively low AdipoR2 may contribute to the inflammatory state seen in ESRD patients.

\section{ADIPONECTIN AND CARDIOVASCULAR DISEASE IN ESRD PATIENTS}

Adiponectin exerts its anti-atherosclerotic effects through multiple actions. It suppresses macrophageto-foam cell transformation and retards human aortic smooth muscle cell proliferation, while local injection into atherosclerotic plaque reduces the development of atherosclerosis by attenuating the expression of vascular cell adhesion molecule- 1 and intercellular adhesion molecule- 1 in vessel walls. ${ }^{76-78}$ The vascularprotective activities of adiponectin have been attributed to the HMW isoform. ${ }^{79}$ In spite of the cardioprotective properties attributed to adiponectin, cardiovascular complications remain the main cause of mortality in the ESRD population..$^{80}$ ESRD is characterized by an exceptional mortality rate, primarily due to a process of inflammation-associated accelerated atherosclerosis. ${ }^{81}$ 
It is currently not clear whether adiponectin in ESRD patients plays the same role as in the general population or if the uremic environment overwhelms the adiponectin cardioprotective impact. The directions of the relationships between adiponectin and several metabolic risk factors, such as cholesterol, HDL cholesterol and markers of inflammation, are all in agreement with the hypothesis that adiponectin may have a protective role for the cardiovascular system among CKD patients. ${ }^{82}$ Several studies support the protective role of adiponectin in the development of new cardiovascular events in patients with ESRD. ${ }^{7,45,64,83}$ Other studies support the hypothesis that high adiponectin predicts increased cardiovascular mortality in ESRD patients. ${ }^{84-86}$

According to a recent study by Tung et $\mathrm{al}^{47}$ specifically in PD patients during a 3.5-year follow-up, the results of the Kaplan-Meier survival analysis demonstrated fewer cardiovascular events and better survival in high adiponectin patients. On multivariate Cox regression analysis, only adiponectin level, age and history of cardiovascular diseases were independent risk factors for future cardiovascular events.

Kistorp and coworkers (2005) showed that high adiponectin levels predicted mortality in a cohort of patients with chronic heart failure, an association they ascribed to confounding due to cachexia, ${ }^{87}$ since reduction in body weight can regulate the synthesis of adiponectin. Therefore, it is necessary to clarify whether increased levels of adiponectin may be involved in the pathogenesis of heart failure or if they simply reflect the degree of cachexia in these patients.

Two groups propose that the ratio of the isoforms of adiponectin is important for the prevention of atherosclerosis. ${ }^{88,89}$ Furthermore, the literature suggests that comparing low, medium- and high-molecularweight adiponectin, the protective effect of adiponectin appears to be linked to its higher molecular weight fraction. ${ }^{90,91}$ This raises the possibility that the heterogeneous epidemiological findings reported so far for total adiponectin could relate to the different proportions of HMW adiponectin. Rao and colleagues have emphasized that the relationship between adiponectin levels and cardiovascular disease in ESRD may not be linear but quadratic, with extreme adiponectin levels associated with worse outcomes. ${ }^{32}$
Thus, despite the existence of strong experimental evidence, prospective epidemiological studies have demonstrated inconsistent results as to the association between adiponectin and cardiovascular disease risk and/or associated mortality. Several explanations exist for these conflicting results including population characteristics such as diabetes, case mix, confounding influences of covariates including inflammation and nutritional status, possibly variants in the gene encoding adiponectin and possible differential retention of the HMW adiponectin isoform in kidney disease.

Nevertheless, since adiponectin exhibits antiatherogenic properties, therapies aimed at raising adiponectin levels could be potentially beneficial in the prevention or treatment of cardiovascular diseases in ESRD patients. In a randomized crossover trial, ${ }^{94}$ oral treatment with pioglitazone, a PPAR- $\gamma$ agonist, significantly improved insulin resistance, reduced inflammation and increased adiponectin in PD patients.

\section{ADIPONECTIN AND WASTING IN ESRD}

Protein-energy wasting is increasingly recognized as a prevalent and significant contributor to poor clinical outcome in dialysis patients. ${ }^{93}$ Protein-energy wasting can be characterized by hypoalbuminemia, low protein or energy intake, reduced muscle mass and body fat. Its major causes include inflammation, inadequate nutrient intake, losses of nutrients during dialysis, acidemia and hormonal disorders. ${ }^{58}$

A syndrome of adverse changes in nutrition and body composition is highly prevalent in patients with $\mathrm{CKD}$, especially in those undergoing dialysis, and it is associated with high morbidity and mortality. ${ }^{94}$ Although insufficient food intake (true undernutrition) due to poor appetite and dietary restrictions contributes to these problems, there are features of the syndrome that cannot be explained by undernutrition alone. Many contributing causes are directly related to kidney disease, including increased resting energy expenditure, persistent inflammation, acidosis, multiple endocrine disorders and the dialysis procedure itself.

In wasting diseases such as $\mathrm{CKD}$, the accelerated loss of fat mass and lean body mass alters the normal regulation of adiponectin. A nested case-control study showed that high adiponectin reflects the degree of 
systemic wasting that precedes death.${ }^{95}$ In two recent studies, serum adiponectin levels in HD patients were reported to have positive correlations with the subjective global assessment and malnutrition-inflammation score and also negative correlations with BMI, meaning that well-nourished HD patients with higher BMI were found to have lower serum adiponectin levels compared to malnourished HD patients with lower BMI. $^{96,97}$

Increased adiponectin has been proposed as being a "reparatory response" to the microvascular insults in uremia.$^{98}$ However, rodent experimental data indicate that adiponectin may also induce protein-energy wasting by increasing energy expenditure and inducing weight loss through a direct effect on the brain. ${ }^{99}$ Kaynar and colleagues found a significant positive correlation between presence of protein-energy wasting and serum adiponectin levels among dialysis patients. ${ }^{100}$ According to Coope et al, adiponectin acts in the hypothalamus through the AdipoR1 receptor and promotes reduction of food intake. ${ }^{25}$ The authors showed that intracerebroventricular injection of recombinant rat adiponectin promoted an anorexigenic state in rats with a $40 \%$ reduction in food intake. Conversely, Kubota and coworkers have shown that peripheral injection of adiponectin enhances AMPK activity in the hypothalamus of mice via AdipoR1 to stimulate food intake and decrease energy expenditure. ${ }^{24}$ These controversial results could be due to the different experimental protocols used by the two groups. Clearly, further studies are needed to clarify the role of adiponectin in the pathogenesis of wasting in ESRD.

\section{ADIPONECTIN AND OUTCOME IN ESRD}

Epidemiological evidence in ESRD has shown conflicting results regarding the association between levels of adiponectin and occurrence of adverse outcomes, relating both hyperadiponectinemia and hypoadiponectinemia to better outcomes. . $^{7,5,64,83,85,86,101}$ A recent 3.5-year follow-up study by Tung et $\mathrm{al}^{47}$ investigated the association of adiponectin and clinical outcomes, specifically in the least studied ESRD population, prevalent PD patients. Their results demonstrate better survival in high adiponectin patients. On the other hand, a recent study in HD patients suggested that high circulating adiponectin is associated with increased overall mortality and that hypoadiponectinemia is associated with better clinical outcome. ${ }^{86}$ Since high adiponectin levels may reflect an ongoing wasting process or may even promote increased energy expenditure, this could explain why hyperadiponectinemia is linked to increased mortality in kidney patients. ${ }^{99}$

Unlike among the healthy population, in HD patients obesity is paradoxically associated with better outcomes, meaning that patients with higher BMI body have better nutritional status. ${ }^{96}$ However, the effect of overweight or obesity on survival of PD patients is less clear with contradictory results. ${ }^{102,103}$ Due to the inverse relationship between adiponectin and fat mass, HD patients with higher adiponectin have lower BMI and subsequently higher risk for mortality. In support of this, adiponectin was not a significant predictor of mortality when wasted patients (serum albumin $\leq 35 \mathrm{~g} / \mathrm{l}$ ) were excluded in a study of HD patients. ${ }^{84}$

Data in HD patients point to nonlinear associations between this adipokine and adverse clinical outcomes, implying that there may be lower and upper thresholds defining an optimal range of levels associated with improved outcomes. ${ }^{32}$ Accordingly, poor outcomes occur with very low and very high adiponectin levels, the latter possibly occurring as a cellular response to malnutrition and declining BMI, or to pro-atherogenic inflammatory stimuli that are associated with malnutrition. ${ }^{104,105}$ According to Tsigalou and colleagues, the differential effect of adiponectin regarding survival on dialysis patients probably resides in the obesity-inflammation association. ${ }^{106}$ They found a U-shaped association of BMI with all-cause mortality in HD patients and an inverse U-shaped association for plasma adiponectin levels and all-cause mortality. The authors postulate that the beneficial effects of adiponectin on inflammatory imbalance are only evident in the presence of adiposity and in the absence of protein-energy wasting.

The relationship between adiponectin and clinical outcomes may be modified by differential retention of high-molecular weight forms of adiponectin in renal failure, the nutritional and inflammatory status and combinations of these factors. Further studies 
are necessary to provide conclusive results about the relationship between adiponectin and outcome.

\section{CONCLUSIONS}

Adiponectin is a key adipokine with multiple actions in the human body. Among the adiponectin isoforms, the multimeric HMW seems to have the most important biological role in peripheral tissues. Despite elevated plasma adiponectin levels in ESRD, adiponectin production is increased in these patients. Moreover, the levels of the HMW isoform are elevated in ESRD. Although the association between adiponectin and cardiovascular disease risk in ESRD remains controversial, hypoadiponectinemia is associated with both insulin resistance and inflammation. Several recent studies in ESRD patients, point to nonlinear associations between adiponectin and clinical outcomes, linking high adiponectin levels to protein-energy wasting. Although adiponectin is most likely secreted to alleviate inflammatory or vascular injuries in ESRD patients, this counter-regulation may be insufficient to improve outcomes due to the toxic vascular effects of the pro-atherogenic uremic milieu. Alternatively, uremia may confer selective adiponectin resistance in specific target organs, whereby protective pathways in peripheral tissues are blocked but the wasting process may be triggered, probably by a different adiponectin isoform, via signals to the central nervous system. Further research will be required to fully elucidate adiponectin metabolism in ESRD patients.

\section{REFERENCES}

1. Waki H, Tontonoz P, 2007 Endocrine Functions of Adipose Tissue. Annu Rev Pathol-Mech 2: 31-56.

2. Shehzad A, Iqbal W, Shehzad O, Lee YS, 2012 Adiponectin: regulation of its production and its role in human diseases. Hormones 11: 8-20.

3. Maeda K, Okubo K, Shimomura I, Funahashi T, Matsuzawa Y, Matsubara K, 1996 cDNA cloning and expression of a novel adipose specific collagen-like factor, apM1 (AdiPose most abundant gene transcript 1). Biochem Biophys Res Commun 221: 286-289.

4. Kadowaki T, Yamauchi T, Kubota N, Hara K, Ueki K, Tobe K, 2006 Adiponectin and adiponectin receptors insulin resistance, diabetes, and the metabolic syndrome. J Clin Invest 116: 1784-1792.

5. Aprahamian TR, Sam F, 2011 Adiponectin in Cardio- vascular Inflammation and Obesity. Int J Inflam 2011: 376909-376917.

6. Nanayakkara PW, Le Poole CY, Fouque D, et al, 2009 Plasma adiponectin concentration has an inverse and a non linear association with estimated glomerular filtration rate in patients with K/DOQI 3 - 5 chronic kidney disease. Clin Nephrol 72: 21-30.

7. Zoccali C, Mallamaci F, Tripepi G, et al, 2002 Adiponectin, metabolic risk factors, and cardiovascular events among patients with end-stage renal disease. J Am Soc Nephrol 13: 134-141.

8. Kato S, Chmielewski M, Honda H, et al, 2008 Aspects of immune dysfunction in end-stage renal disease. Clin J Am Soc Nephrol 3: 1526-1533.

9. Pozzoni P, Del Vecchio L, Pontoriero G, Di Filippo S, Locatelli F, 2004 Long-term outcome in hemodialysis: Morbidity and mortality. J Nephrol 17: 87-95.

10. Guebre-Egziabher F, Drai J, Fouque D, 2007 Adiponectin and chronic kidney disease. J Ren Nutr 17: 9-12.

11. Kissebah AH, Sonnenberg GE, Myklebust J, et al, 2000 Quantitative trait loci on chromosomes 3 and 17 influence phenotypes of the metabolic syndrome. Proc Natl Acad Sci USA 97: 14478-14483.

12. Berg AH, Combs TP, Scherer PE, 2002 ACRP30/adiponectin: an adipokine regulating glucose and lipid metabolism. Trends Endocrinol Metab 13: 84-89.

13. Scherer PE, Williams S, Fogliano M, Baldini G, Lodish $\mathrm{HF}, 1995$ A novel serum protein similar to $\mathrm{C} 1 \mathrm{q}$, produced exclusively in adipocytes. J Biol Chem 270: 26746-26749.

14. Nakano Y, Tobe T, Choi-Miura NH, Mazda T, Tomita M, 1996 Isolation and characterization of GBP28, a novel gelatin-binding protein purified from human plasma. $\mathrm{J}$ Biochem 120: 803-812.

15. Tsao TS, Tomas E, Murrey HE, et al, 2003 Role of disulfide bonds in Acrp30/adiponectin structure and signaling specificity - Different oligomers activate different signal transduction pathways. J Biol Chem 278: 50810-50817.

16. Fruebis J, Tsao T-S, Javorschi S, et al, 2001 Proteolytic cleavage product of $30-\mathrm{kDa}$ adipocyte complementrelated protein increases fatty acid oxidation in muscle and causes weight loss in mice. Proc Natl Acad Sci USA 98: 2005-2010.

17. Wang Y, Lam KSL, Chan L, et al, 2006 Post-translational modifications of the four conserved lysine residues within the collagenous domain of adiponectin are required for the formation of its high molecular weight oligomeric complex. J Biol Chem 281: 16391-16400.

18. Bobbert T, Rochlitz H, Wegewitz U, et al, 2005 Changes of adiponectin oligomer composition by moderate weight reduction. Diabetes 54: 2712-2719.

19. Yamauchi T, Kamon J, Ito Y, et al, 2003 Cloning of adiponectin receptors that mediate antidiabetic metabolic effects. Nature 423: 762-769.

20. Yamauchi T, Kadowaki T, 2013 Adiponectin Receptor 
as a key player in healthy longevity and obesity-related diseases. Cell Metab 17: 185-196.

21. Yamauchi T, Kamon J, Minokoshi Y, et al, 2002 Adiponectin stimulates glucose utilization and fatty-acid oxidation by activating AMP-activated protein kinase. Nat Med 8: 1288-1295.

22. Yamauchi T, Nio Y, Maki T, et al, 2007 Targeted disruption of AdipoR1 and AdipoR2 causes abrogation of adiponectin binding and metabolic actions. Nat Med 13: 332-339.

23. Kadowaki T, Yamauchi T, 2005 Adiponectin and adiponectin receptors. Endocr Rev 26: 439-451.

24. Kubota N, Yano W, Kubota T, et al, 2007 Adiponectin stimulates AMP-activated protein kinase in the hypothalamus and increases food intake. Cell Metab 6: 55-68.

25. Coope A, Milanski M, Araujo EP, et al, 2008 AdipoR1 mediates the anorexigenic and insulin/leptin-like actions of adiponectin in the hypothalamus. FEBS Lett 582: 1471-1476.

26. Aroda V, Ciaraldi TP, Chang SA, Dahan MH, Chang RJ, Henry RR, 2008 Circulating and cellular adiponectin in polycystic ovary syndrome: relationship to glucose tolerance and insulin action. Fertil Steril 89: 1200-1208.

27. Glintborg D, Frystyk J, Hojlund K, et al, 2008 Total and high molecular weight (HMW) adiponectin levels and measures of glucose and lipid metabolism following pioglitazone treatment in a randomized placebocontrolled study in polycystic ovary syndrome. Clin Endocrinol 68: 165-174.

28. Arita Y, Kihara S, Ouchi N, et al, 1999 Paradoxical decrease of an adipose-specific protein, adiponectin, in obesity. Biochem Biophys Res Commun 257: 79-83.

29. Madsen EL, Rissanen A, Bruun JM, et al, 2008 Weight loss larger than $10 \%$ is needed for general improvement of levels of circulating adiponectin and markers of inflammation in obese subjects: a 3-year weight loss study. Eur J Endocrinol 158: 179-187.

30. Lara-Castro C, Doud EC, Tapia PC, et al, 2008 Adiponectin Multimers and Metabolic Syndrome Traits: Relative Adiponectin Resistance in African Americans. Obesity 16: 2616-2623.

31. Zoccali C, Mallamaci F, Panuccio V, et al, 2003 Adiponectin is markedly increased in patients with nephrotic syndrome and is related to metabolic risk factors. Kidney Int Suppl 84: 98-102.

32. Rao M, Lijun L, Tighiouart H, Jaber BL, Pereira BG, 2008 Vaidyanathapuram S. Plasma adiponectin levels and clinical outcomes among hemodialysis patients Nephrol Dial Transplant 23: 2619-2628.

33. Doumatey AP, Zhou J, Huang H, et al, 2012 Circulating adiponectin is associated with renal function independent of age and serum lipids in west Africans. Int $\mathrm{J}$ Nephrol 2012: 1-8.

34. Lim CC, Teo BW, Tai ES, et al, 2015 Elevated Serum Leptin, Adiponectin and Leptin to Adiponectin Ratio
Is Associated with Chronic Kidney Disease in Asian Adults. PLoS ONE 10: e0122009.

35. Park JT, Yoo T-H, Kim J-K, et al, 2013 Leptin/Adiponectin Ratio Is an Independent Predictor of Mortality in Nondiabetic Peritoneal Dialysis Patients. Perit Dial Int 33: 67-74.

36. Iwashima Y, Horio T, Kumada M, et al, 2006 Adiponectin and renal function, and implication as a risk of cardiovascular disease. Am J Cardiol 98: 1603-1608.

37. Stenvinkel P, Marchlewska A, Pecoits-Filho R, et al, 2004 Adiponectin in renal disease: relationship to phenotype and genetic variation in the gene encoding adiponectin. Kidney Int 65: 274-281.

38. Huang JW, Yen CJ, Chiang HW, Hung KY, Tsai TJ, Wu KD. 2004 Adiponectin in peritoneal dialysis patients: a comparison with hemodialysis patients and subjects with normal renal function. Am J Kid Dis 43: 1047-1055.

39. Shen YY, Charlesworth JA, Kelly JJ, Loi KW, Peake PW, 2007 Up-regulation of adiponectin, its isoforms and receptors in end-stage kidney disease. Nephrol Dial Transplant 22: 17171-17810.

40. Pham PC, Pham PM, Pham SV, Miller JM, Pham PT, 2007 Hypomagnesemia in patients with type 2 diabetes. Clin J Am Soc Nephrol 2: 366-373.

41. Whitehead JP, Richards AA, Hickman IJ, Macdonald GA, Prins JB, 2006 Adiponectin - a key adipokine in the metabolic syndrome. Diabetes Obes Metab 8: 264-280.

42. Hotta K, Funahashi T, Arita Y, et al, 2000 Plasma concentrations of a novel, adipose-specific protein, adiponectin, in type 2 diabetic patients. Arterioscler Thromb Vasc Biol 20: 1595-1599.

43. Iwashima Y, Katsuya T, Ishikawa K, et al, 2005 Association of hypoadiponectinemia with smoking habit in men. Hypertension 45:1094-1100.

44. Dzielińska Z, Januszewicz A, Więcek A, et al, 2003 Decreased plasma concentration of a novel anti-inflammatory protein-adiponectin-in hypertensive men with coronary artery disease. Thromb Res 110: 365-369.

45. Abdallah E, Waked E, Nabil M, El-Bendary O. 2012 Adiponectin and Cardiovascular Outcomes among Hemodialysis Patients. Kidney Blood Press Res 35: 247-253.

46. Markaki A, Gkouskou K, Stylianou K, et al, 2014 Relationship between adiposity, adipokines, inflammatory markers and lipid profile in hemodialysis patients. Eur Rev Med Pharmacol Sci 18: 1496-1498.

47. Tung CW, Hsu YC, Shih YH, Lin CL, 2015 Association of Adiponectin with High-Sensitivity C-Reactive Protein and Clinical Outcomes in Peritoneal Dialysis Patients: A 3.5-Year Follow-Up Study. PLoS One 16: e0141058.

48. Adamczak M, Chudek J, Wiecek A, 2009 Adiponectin in patients with chronic kidney disease. Semin Dial 22: 391-395.

49. Guebre-Egziabher F, Bernhard J, Funahashi T, HadjAissa A, Fouque D, 2005 Adiponectin in chronic kidney disease is related more to metabolic disturbances than to decline in renal function. Nephrol Dial Transplant 
20: $129-134$.

50. Chudek J, Adamczak M, Karkoszka H, et al, 2003 Plasma adiponectin concentration before and after successful kidney transplantation. Transplant Proc 35: 2186-2189.

51. Malyszko J, Malyszko JS, Brzosko S, Wolczynski S, Mysliwiec M, 2010 Markers of endothelial cell activation/injury: CD146 and thrombomodulin are related to adiponectin in kidney allograft recipients. Am J Nephrol 25: 203-210.

52. Martinez Cantarin MP, Waldman SA, Doria C, et al, 2013 The adipose tissue production of adiponectin is increased in end-stage renal disease. Kidney Int 83: 487-494.

53. Martinez Cantarin MP, Keith SW, Waldman SA, Falkner B, 2014 Adiponectin receptor and adiponectin signaling in human tissue among patients with end-stage renal disease. Nephrol Dial Transplant 29: 2268-2277.

54. Yoon MJ, Lee GY, Chung JJ, et al, 2006 Adiponectin increases fatty acid oxidation in skeletal muscle cells by sequential activation of AMP-activated protein kinase, p38 mitogen-activated protein kinase, and peroxisome proliferator-activated receptor alpha. Diabetes 55: 2562-2570.

55. DeFronzo RA, Alvestrand A, Smith D, et al, 1981 Insulin resistance in uremia. J Clin Invest 67: 563-568.

56. Kobayashi S, Maesato K, Moriya H, Ohtake T, Ikeda T, 2005 Insulin resistance in patients with chronic kidney disease. Am J Kidney Dis 45:275-280.

57. Shinohara K, Shoji T, Emoto M, et al, 2002 Insulin resistance as an independent predictor of cardiovascular mortality in patients with end-stage renal disease. J Am Soc Nephrol 13: 1894-1900.

58. Fouque D, Kalantar-Zadeh K, Kopple J, et al, 2008 A proposed nomenclature and diagnostic criteria for protein-energy wasting in acute and chronic kidney disease. Kidney Int 73: 391-398.

59. Barazzoni R, 2012 Adipokines, ghrelin and obesityassociated insulin resistance in nondiabetic patients with acute coronary syndrome. Obesity 20: 2348-2353.

60. Pajvani UB, Hawkins M, Combs TP, et al, 2004 Complex distribution, not absolute amount of adiponectin, correlates with thiazolidinedione-mediated improvement in insulin sensitivity. J Biol Chem 279: 12152-12162.

61. Liu M, Liu F, 2010 Transcriptional and post-translational regulation of adiponectin. Biochem J 425: 41-52.

62. Lara-Castro C, Luo N, Wallace P, Klein RL, Garvey WT, 2006 Adiponectin multimeric complexes and the metabolic syndrome trait cluster. Diabetes 55: 249-259.

63. Becker B, Kronenberg F, Kielstein JT, Haller H, Morath C, Ritz E, 2005 Renal insulin resistance syndrome, adiponectin and cardiovascular events in patients with kidney disease: the mild and moderate kidney disease study. J Am Soc Nephrol 16: 1091-1098.

64. Elokely A, Shoukry A, Ghonemy TA, Atia M, Amr G, 2012 Association of adiponectin with cardiovascular events in diabetic and non-diabetic hemodialysis patients.
Saudi J Kidney Dis Transpl 23: 736-742.

65. Giers K, Niemczyk S, Szamotulska K, et al, 2015 Visceral Adipose Tissue is Associated with Insulin Resistance in Hemodialyzed Patients. Med Sci Monit 21: 557-562.

66. Lin HV, Kim JY, Pocai A, et al, 2007 Adiponectin resistance exacerbates insulin resistance in insulin receptor transgenic/knockout mice. Diabetes 56: 1969-1976.

67. Bruce CR, Mertz VA, Heigenhauser GJ, Dyck DJ, 2005 The stimulatory effect of globular adiponectin on insulin-stimulated glucose uptake and fatty acid oxidation is impaired in skeletal muscle from obese subjects. Diabetes 54: 3154-3160.

68. Chen MB, McAinch AJ, Macaulay SL, et al, 2005 Impaired activation of AMP-kinase and fatty acid oxidation by globular adiponectin in cultured human skeletal muscle of obese type 2 diabetics. J Clin Endocrinol Metab 90: 3665-3672.

69. Welters ID, Bing C, Ding C, Leuwer M, Hall AM, 2014 Circulating anti-inflammatory adipokines High Molecular Weight Adiponectin and Zinc-alpha2-glycoprotein (ZAG) are inhibited in early sepsis, but increase with clinical recovery: a pilot study. BMC Anesthesiol 14: 124-133.

70. Stenvinkel P, 2006 Inflammation in end-stage renal disease: the hidden enemy. Nephrology 11: 36-41.

71. Krysiak R, Handzlik-Orlik G, Okopien B, 2012 The Role of Adipokines in Connective Tissue Diseases. Eur J Nutr 51: 513-528.

72. Almer G, Saba-Lepek M, Haj-Yahya S, et al, 2011 Globular domain of adiponectin: promising target molecule for detection of atherosclerotic lesions. Biologics 5: 95-105.

73. Ouchi N, Kihara S, Funahashi T, et al, 2003 Reciprocal association of C-reative protein with adiponectin in blood stream and adipose tissue. Circulation 107: 671-674.

74. Engeli S, Feldpausch M, Gorzelniak K, et al, 2003 Association between adiponectin and mediators of inflammation in obese women. Diabetes 52: 942-947.

75. Fernandez-Real JM, Lopez-Bermejo A, Casamitjana R, Ricart W. 2003 Novel interactions of adiponectin with the endocrine system and inflammatory parameters. J Clin Endocrin \& Metab 88: 2714-2718.

76. Ouchi N, Kihara S, Arita Y, et al, 2001 Adipocytederived plasma protein, adiponectin, suppresses lipid accumulation and class A scavenger receptor expression in human monocyte-derived macrophages. Circulation 103: 1057-1063.

77. Arita Y, Kihara S, Ouchi N, et al, 2002 Adipocyte-derived plasma protein adiponectin acts as a platelet-derived growth factor-BB-binding protein and regulates growth factor-induced common post receptor signal in vascular smooth muscle cell. Circulation 18: 2893-2898.

78. Li CJ, Sun HW, Zhu FL, et al, 2007 Local adiponectin treatment reduces atherosclerotic plaque size in rabbits. J Endocrinol 193: 137-145.

79. Giannessi D, Maltinti M, Del Ry S, 2007 Adiponectin 
circulating levels: a new emerging biomarker of cardiovascular risk. Pharmacol Res 56: 459-467.

80. Collins AJ, 2003 Cardiovascular mortality in end-stage renal disease. Am J Med Sci 325: 163-167.

81. Panichi V, Scatena A, Migliori M, Marchetti V, Paoletti S, Beati S, 2012 Biomarkers of Chronic Inflammatory State in Uremia and Cardiovascular Disease. Int J Inflam 2012: 1-6.

82. Zoccali, C, Benedetto FA, Mallamaci F, et al, 2000 Inflammation is associated with carotid atherosclerosis in dialysis patients. Creed Investigators Cardiovascular Risk Extended Evaluation in Dialysis Patients J Hypertens 18: 1207-1213.

83. El-Shafey EM, Shalan M, 2014 Plasma adiponectin levels for prediction of cardiovascular risk among hemodialysis patients. Ther Apher Dial 18: 185-192.

84. Ohashi N, Kato A, Misaki T, et al, 2008 Association of serum adiponectin levels with all-cause mortality in hemodialysis patients. Intern Med 47: 485-491.

85. Jorsal A, Tarnow L, Frystyk J, et al, 2008 Serum adiponectin predicts all-cause mortality and end stage renal disease in patients with type I diabetes and diabetic nephropathy. Kidney Int 74: 649-654.

86. Tamadon MR, Heidari M, Dris F, Mardani S, 2015 Correlation of serum adiponectin level with some biochemical and metabolic factors in stable hemodialysis patients. J Parathyr Dis 3: 20-24.

87. Kistorp C, Faber J, Galatius S, et al, 2005 Plasma adiponectin, body mass index, and mortality in patients with chronic heart failure. Circulation 112: 1756-1762.

88. Kobayashi H, Ouchi N, Kihara S, et al, 2004 Selective suppression of endothelial cell apoptosis by the high molecular weight form of adiponectin. Circ Res 94: 27-31.

89. Aso Y, Yamamoto R, Wakabayashi S, et al, 2006 Comparison of serum high-molecular weight (HMW) adiponectin with total adiponectin concentrations in type 2 diabetic patients with coronary artery disease using a novel enzyme-linked immunosorbent assay to detect HMW adiponectin. Diabetes 55: 1954-1960.

90. Iwasa Y, Otsubo S, Ishizuka T, Uchida K, Nitta K, 2008 Influence of serum high-molecular-weight and total adiponectin on arteriosclerosis in IgA nephropathy patients. Nephron Clin Pract 108: 226-232.

91. Tomizawa A, Hattori Y, Kasai K, Nakano Y, 2008 Adiponectin induces NF-kappa B activiation that leads to suppression of cytokine-induced NF-kappa B activation in vascular endothelial cells: globular adiponectin vs. high molecular weight adiponectin. Diab Vasc Dis Res 5: 123-127.

92. Li Y, Xie QH, You HZ, et al, 2012 Twelve weeks of pioglitazone therapy significantly attenuates dysmetabolism and reduces inflammation in continuous ambulatory peritoneal dialysis patients-a randomized crossover trial. Perit Dial Int 32: 507-515.

93. Kovesdy CP, George SM, Anderson JE, Kalantar-Zadeh K, 2009 Outcome predictability of biomarkers of protein-energy wasting and inflammation in moderate and advanced chronic kidney disease Am J Clin Nutr 90: 407-414

94. Carrero JJ, Stenvinkel P, Cuppari L, Ikizler TA, KalantarZadeh K, 2013 Etiology of the Protein-Energy Wasting Syndrome in Chronic Kidney Disease: A Consensus Statement From the International Society of Renal Nutrition and Metabolism (ISRNM). J Ren Nutr 23: 77-90.

95. Matsumoto S, Hyodo F, Subramanian S, et al, 2008 Low-field paramagnetic resonance imaging of tumor oxygenation and glycolytic activity in mice. J Clin Invest 118: 1965-1973.

96. Malgorzewicz S, Aleksandrowicz-Wrona E, Owczarzak A, Debska-Slizien A, Rutkowski B, Lysiak-Szydlowska W, 2010 Adipokines and nutritional status for patients on maintenance hemodialysis. J Ren Nutr 20: 303-308.

97. Lee S, Park Y, Dellsperger KC, Zhang C, 2011 Exercise training improves endothelial function via adiponectindependent and independent pathways in type 2 diabetic mice. Am J Physiol Heart Circ Physiol 301: 306-314.

98. Drechsler C, Krane V, Winkler K, Dekker FW, Wanner C, 2009 Changes in adiponectin and the risk of sudden death, stroke, myocardial infarction, and mortality in hemodialysis patients. Kidney Int 76: 567-575.

99. Qi Y, Takahashi N, Hileman SM, et al, 2004 Adiponectin acts in the brain to decrease body weight. Nat Med 10: 524-529.

100. Kaynar K, Kural BV, Ulusoy S, et al, 2014 Is there any interaction of resistin and adiponectin levels with protein-energy wasting among patients with chronic kidney disease. Hemodial Int 18: 153-162.

101. Ignacy W, Chudek J, Adamczak M, et al, 2005 Reciprocal association of plasma adiponectin and serum C-reactive protein concentration in haemodialysis patients with end-stage kidney disease--a follow-up study. Nephron Clin Pract 101: 18-24.

102. McDonald SP, Collins JF, Johnson DW, 2003 Obesity is associated with worse peritoneal dialysis outcomes in the Australia and New Zealand patient populations. J Am Soc Nephrol 14: 2894-2901.

103. Pliakogiannis T, Trpeski L, Taskapan H, et al, 2007 Reverse epidemiology in peritoneal dialysis patients: the Canadian experience and review of the literature. Int Urol Nephrol 39: 281-288.

104. Pecoits-Filho R, Lindholm B, Stenvinkel P, 2002 The malnutrition, inflammation, and atherosclerosis (MIA) syndrome-the heart of the matter. Nephrol Dial Transplant 17: 28-31.

105. Shoji T, Shinohara K, Hatsuda S, et al, 2015 Altered relationship between body fat and plasma adiponectin in end-stage renal disease. Metabolism 54: 330-334.

106. Tsigalou C, Chalikias G, Kantartzi K, et al, 2013 Differential effect of baseline adiponectin on all-cause mortality in hemodialysis patients depending on initial body mass index. Long-term follow-up data of 4.5 years. J Ren Nutr 23: 45-56. 